\title{
Internal thoracic vein injury presenting as extrapericardial tamponade after blunt chest trauma
}

\author{
Kyung Hwa Kim, MD, PhD, Jong Bum Choi, MD, PhD, and Min Ho Kim, MD, PhD
}

Mediastinal hematoma has been reported in association with cardiac tamponade in several clinical settings. A 32year-old man came to our trauma unit after being crushed under a persimmon tree that fell from about $5 \mathrm{~m}$ in height. Initial hemodynamic status was unstable, with blood pressure $70 / 40 \mathrm{~mm} \mathrm{Hg}$, pulse rate 130 beats/min, and central venous pressure $22 \mathrm{~cm} \mathrm{H}_{2} \mathrm{O}$. A chest radiograph (Figure 1) showed disappearance of sharp cardiac silhouette with left rib fracture. Computed tomography showed a large anterior mediastinal hematoma with left internal thoracic vessel extravasation (Figure 2, A) and sternal body fracture (Figure 2, B). The patient underwent emergency sternotomy with evacuation of a retrosternal hematoma. Actively bleeding vessels were both internal thoracic veins (intact internal thoracic artery). The patient was stable in the postoperative period and was discharged after 2 weeks.

\footnotetext{
From the Department of Cardiothoracic and Vascular Surgery, Chonbuk National University Medical School, Jeonju, Republic of Korea.

Disclosures: Authors have nothing to disclose with regard to commercial support.

Received for publication Oct 15, 2012; accepted for publication Nov 6, 2012; available ahead of print Dec 10, 2012

Address for reprints: Kyung Hwa Kim, MD, PhD, Department of CardioThoracic and Vascular Surgery, Chonbuk National University Medical School, San 2-20 Geumam-dong, Deokjin-gu, Jeonju, Jeonbuk 561-180, South Korea (E-mail: tcskimgh@gmail.com).

J Thorac Cardiovasc Surg 2013;145:1130

0022-5223/\$36.00

Crown Copyright (C) 2013 Published by Elsevier Inc. on behalf of The American Association for Thoracic Surgery

http://dx.doi.org/10.1016/j.jtcvs.2012.11.023
}

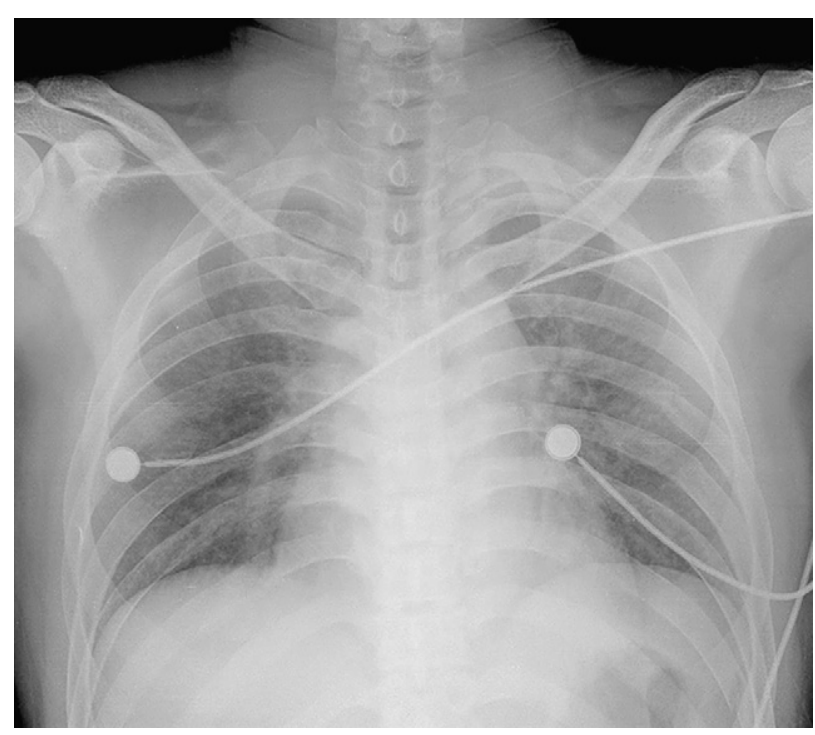

FIGURE 1. A chest radiograph showed no remarkable findings other than a left rib fracture.
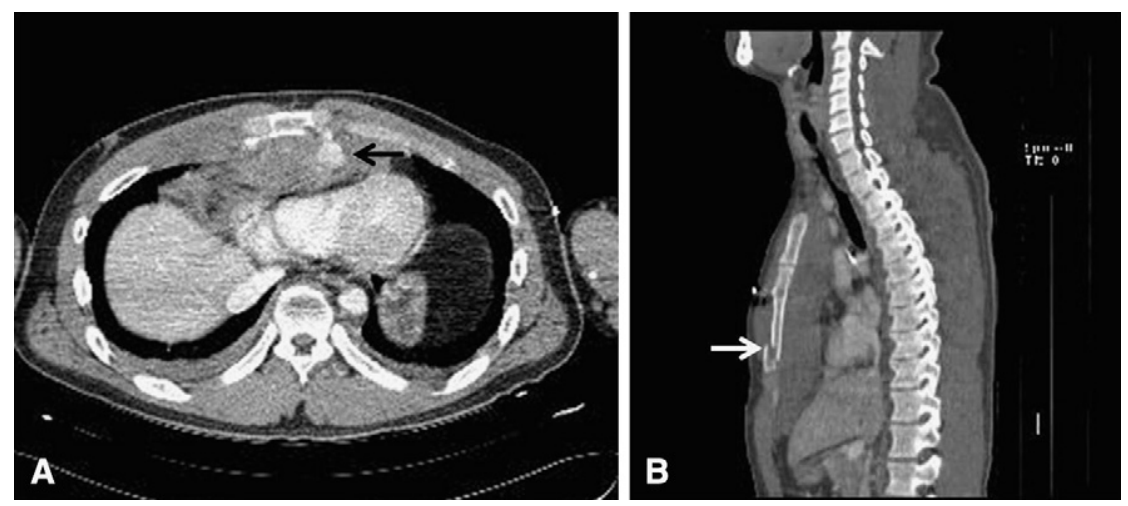

FIGURE 2. Computed tomography showed a large anterior mediastinal hematoma with left internal thoracic vessel extravasation (A, arrow) and severe compressed heart and sternal body fracture (B, arrow). 